\title{
Vídeo e Ação: a Matemática na solução de Mistérios
}

Fabiana Fattore Serres - fabiana.serres@ufrgs.br-CAP-UFRGS ${ }^{1}$

Marcus Vinicius de Azevedo Basso - mbasso@ufrgs.br - IM-UFRGS ${ }^{2}$

Luiz Davi Mazzei - coffey@terra.com.br - Cap-UFRGS

Colégio de Aplicação - Instituto de Matemática

Universidade Federal do Rio Grande do Sul (UFRGS)

Porto Alegre - RS - Brasil

\section{Resumo}

Esse trabalho apresenta uma experiência pedagógica na qual os alunos do primeiro ano do ensino médio de uma escola pública são motivados às aulas de Matemática a partir da exibição de episódios da série Num3ers. Utilizando como mote a abordagem apresentada na série, propusemos aos alunos a solução um mistério, partindo de pistas às quais só tinham acesso resolvendo desafios e enigmas matemáticos. Esses desafios utilizavam tanto conceitos matemáticos que os alunos dominavam quanto utilizavam lógica, raciocínio dedutivo e o estabelecimento de relações e observações. Constatamos que essa atividade proporcionou aos alunos um exercício no qual o trabalho cooperativo, a discussão e a argumentação, permitiram que os estudantes construíssem conceitos de matemática ao mesmo tempo em que eles estabelecessem a ideia que a matemática não se constitui numa disciplina que somente adquire sentido no ambiente escolar.

Palavras-chave: cooperação, vídeos, aprendizagem, matemática

\section{Video and Action: The Mathematics in Mystery Solving}

\begin{abstract}
This work presents a pedagogic experiment with high school freshmen students of a public school. They are motivated to mathematics classes by the exhibition of episodes from Numb3ers series. A mystery solving was proposed to scholars using the approach presented in the series as subject. It began with clues only achieved after students had solved mathematical challenges and enigmas. These challenges used mathematical concepts that pupils were familiar with, as logic, deductive reasoning and establishment of relations and observations. It has been verified that this activity offered an exercise in which cooperative work, discussion and argumentation allowed the scholars to construct mathematical concepts. At the same time students could constitute the idea that mathematics is not a discipline that only acquires meaning in school environment.
\end{abstract}

Keywords: cooperation, digital medias, learning, mathematics

\section{Introdução - o contexto de trabalho}

Muitas vezes os alunos não percebem quais as relações que a Matemática, uma das ciências com grandes aplicações no cotidiano deles, guarda com a vida fora do ambiente escolar. Não raro, durante as aulas, ouvimos os alunos perguntarem qual a utilidade da Matemática que estão estudando, ou qual a finalidade de estarem aprendendo determinado conteúdo. Para tentar resolver esse problema, pensamos em uma

\footnotetext{
${ }^{1}$ Colégio de Aplicação - Universidade Federal do Rio Grande do Sul (UFRGS) - Porto Alegre - RS - Brasil

${ }^{2}$ Instituto de Matemática - Universidade Federal do Rio Grande do Sul (UFRGS) - Porto Alegre - RS - Brasil
} 
abordagem diferenciada, que possibilitasse aos alunos visualizar as aplicações da Matemática em contextos diferentes do escolar.

O Colégio de Aplicação da UFRGS (CAp-UFRGS), com o objetivo de proporcionar aos alunos oportunidades de aprendizagem que lhes permitam uma apropriação crítica de conhecimentos e, paralelamente, criando condições para que esses alunos tornem-se aprendizes autônomos, oferece uma disciplina denominada Enriquecimento Curricular (EC). Nessa disciplina, professores especialistas propõem atividades relacionadas com as diversas áreas de conhecimento humano abordando conteúdos das respectivas áreas de especialização e que, usualmente, não seriam abordados em um currículo regular. Os estudantes, por sua vez, têm a oportunidade de escolher qual EC desejam cursar a partir de exposições feitas por esses professores especialistas. As disciplinas de EC têm a duração de 1 hora e 30 minutos com a freqüência de uma vez por semana e em média 15 estudantes por turma. No segundo semestre de 2008, um grupo de licenciandos em Matemática da UFRGS e professores do CAp-UFRGS e Instituto de MatemáticaUFRGS apresentaram a proposta de um EC que consistia em trabalhar conceitos de matemática a partir da série para TV "Numbers". Nessas aulas, apresentávamos aos alunos episódios desta série procurando oferecer atividades que lhes proporcionassem possibilidades de apropriação de conceitos matemáticos, ao mesmo tempo em que permitia que enxergassem aplicações do conteúdo matemático estudado.

Numb3rs é uma série de televisão americana produzida pelos irmãos Ridley Scott e Tony Scott que traz episódios de 50 minutos aproximadamente. $\mathrm{O}$ enredo traz o agente especial do FBI Don Eppes e seu irmão, Charlie Eppes, matemático, que ajuda Don a resolver crimes para o FBI.

Os objetivos dessa proposta foram promover uma discussão sobre as aplicações do conteúdo matemático, estimular o trabalho cooperativo, desenvolver a capacidade de estabelecer relações e generalizações de uma maneira lúdica.

Em nossa proposta levamos em consideração principalmente dois aspectos teóricos, quais sejam: a atual forma do ensino de matemática, que prioriza a reprodução em detrimento da reflexão e o papel da educação escolar na formação social e individual do aluno.

No ensino de matemática muitas vezes é solicitado ao aluno que demonstre possuir noções e conceitos matemáticos e, muitas vezes, pedimos que os apliquem, mas raras vezes solicitamos que discuta e expresse as razões pelas quais escolheu determinada maneira para resolver o problema.

No dizer de Lladó e Jorba (1998) “... O aluno precisa demonstrar que 'possue conhecimentos matemáticos', mas quase nunca se pede que apresente razões para o que faz, que justifique a opção que escolheu para resolver certo problema ou que interprete os resultados numéricos no interior de um determinado contexto. No caso de se pedir que demonstre alguma proposição matemática, sempre se faz no sentido de pedir-lhe que repita alguma demonstração conhecida que, se assim o desejasse, poderia achá-la no livro texto."

Assim, nossa proposta de atividade buscou contemplar opções nas quais os alunos necessariamente utilizaram conceitos matemáticos, aplicando-os, mas sobretudo discutindo, ponderando sobre qual seria a melhor alternativa, analisando os resultados. O trabalho em parceira, coletivo, também prioriza a justificativa sobre a abordagem escolhida, uma vez que todos devem trabalhar em uma mesma opção. Ou seja, a proposta de atividade busca propiciar que os alunos se apropriem de conceitos matemáticos de maneira consciente, baseada na discussão, argumentação, análise e justificativa, na qual o trabalho cooperativo tem papel principal. 
Consideramos também que a educação escolar não é tão-somente um fornecer informações sobre determinados assuntos. De acordo com Coll e Onrubia, 1998, a educação escolar tem dupla vertente a socialização e a individualização. "Socialização porque a educação escolar pressupõe um conjunto de atividades e práticas socialmente estabelecidas e regulamentadas com a finalidade de ajudar os membros do grupo social a assimilar e apropriar-se de idéias, conceitos habilidades, norma de conduta, etc., que se consideram relevantes para a participação na vida adulta, ativa e crítica nesse grupo. Individualização porque permite às crianças e jovens do grupo não somente integraremse ao mesmo e serem capazes de agir como membros adultos do grupo, mas também desenvolverem-se como indivíduos com suas próprias peculiaridades capazes de agir como agentes de mudança e criação cultural."

Nesse sentido, o trabalho proposto buscou estimular não só a socialização, através do trabalho cooperativo, mas também a individualização, no que concerne necessidade que o aluno tinha de expressar sua posição e sustentá-la junto ao grupo.

\section{Desenvolvimento e discussão dos resultados}

\subsection{Episódio piloto EC-Numb3rs}

No nosso primeiro encontro os alunos assistiram o episódio piloto da série, que traz como enredo uma investigação para encontrar um serial killer que age na cidade de Los Angeles. Charlie, ao ler as anotações do irmão, percebe um padrão entre os locais que o assassino age e cria uma equação para tentar prever quais seriam as próximas cenas dos crimes. Ao final do episódio incentivamos uma discussão acerca do que haviam assistido do enredo, dos detalhes que perceberam e de quais conceitos de Matemática eles encontraram na trama. Nesse momento, apresentamos para os alunos a proposta da primeira atividade: Cada estudante recebeu um mapa de uma região de Porto Alegre onde estavam marcados supostos locais de crimes cometidos pelo mesmo assassino e pedimos que eles procurassem um padrão. Também solicitamos que os estudantes marcassem no mapa o provável local onde o assassino agiria na próxima vez e descrevessem com suas palavras a estratégia usada para chegar a essa conclusão. Abaixo destacamos a imagem do mapa de um estudante:

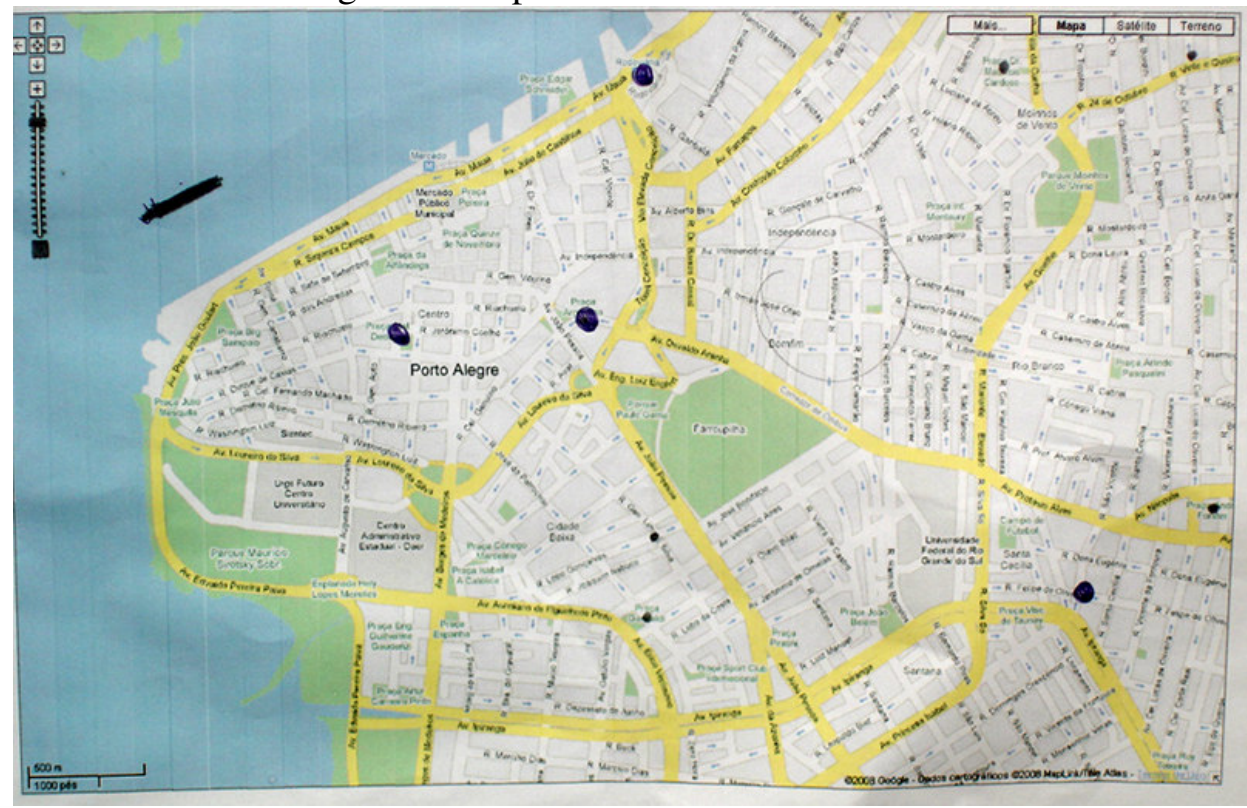

Figura 1 - Imagem exemplificando a primeira atividade 
Os estudantes experimentaram nesta atividade certo estranhamento, uma vez que muitas vezes, não estavam acostumados a "ver" a Matemática de outro ângulo que não aquele trabalhado por seus professores em sala de aula. Como podemos ver na figura 1 o aluno ALFA delimitou uma provável região. Salientamos que essa delimitação deu-se a partir de uma intensa discussão que envolveu, dentre outros aspectos, questões relacionadas com ofertas de emprego na região, onde maior oferta de emprego implicava menor índice de criminalidade, segundo análise do grupo de estudantes. Esse tipo de discussão foi uma constante no trabalho desenvolvido pelos grupos de estudantes e professores.

\subsection{Repensando o EC e mudando a estratégia}

Embora o resultado do trabalho desenvolvido na primeira atividade tenha provocado o envolvimento dos estudantes, percebemos nos encontros seguintes que os estudantes não estavam muito empolgados com repetição do modelo proposto "vídeos-atividades". Ou seja, apenas assistir ao filme e depois realizar uma tarefa não estava provocando o mesmo envolvimento constatado inicialmente. Decidimos então buscar uma nova estratégia para o trabalho. Mas o que poderia motivar os alunos? Pensamos que deveria ser algo que tornasse encontro "mais dinâmico", que eles precisassem "por a mão na massa" e não só assistir. Além disso, essa atividade teria que criar condições para que a proposta do EC mantivesse o seu princípio pedagógico, qual seja o criar um cenário de aprendizagem no qual fossem estabelecidas condições para os estudantes abstraírem, estabelecerem relações entre fatos e informações, interpretarem. De forma cooperativa, a equipe desenvolveu estratégias a partir de um "brainstorm":

"Poderia ser uma caça ao tesouro com pistas em que eles pudessem desvendar um mistério como acontece na série."

"Eles poderiam descobrir onde está alguma coisa importante que foi roubada da escola."

"Poderíamos trabalhar com imagens, uma vez que na série eles sempre analisam fotografias a procura de pistas que auxiliem a solucionar os crimes nas investigações."

"Para a dinâmica funcionar melhor, poderíamos dividir os estudantes em grupos de

2 detetives; assim todos iriam trabalhar e ganharia quem achasse primeiro o que foi roubado."

"Mas o que poderia ter sido foi roubado? Poderia ser o símbolo da escola: A Coruja."

"Isso! Daí poderíamos esconder a coruja em algum lugar e fotografamos este lugar."

\subsection{Atividade Caça a Coruja} definida:

Depois de muito planejamento, a atividade "Caça a Coruja" ficou assim

- dividimos os alunos em duplas de detetives e cada professor ficaria responsável pela dinâmica da atividade de duas delas;

- cada dupla recebeu um envelope, que ficava com o professor responsável, e continha enigmas envolvendo conceitos matemáticos;

- ao resolver um enigma a dupla ou encontrava uma letra como resposta e guardava para formar uma palavra que indicaria o que eles estavam procurando (CORUJA), ou recebiam um pedaço de uma fotografia que juntando todos no final completaria uma imagem de onde estava escondida a Coruja (o refeitório). 
Procuramos enigmas de resolução rápida para que a atividade fosse dinâmica, como destacamos no exemplo a seguir. (figura 2)

Eu sou a letra que se esconde nos

gráficos de $y=3 x$, com domínio de $(0,1)$

imagem de $(0,3), y=-3 x+6$, com dominio

de $(1,2)$ e imagem de $(0,3)$ e $y=3 / 2 \mathrm{com}$

dominio de $(0,5,1,5)$.

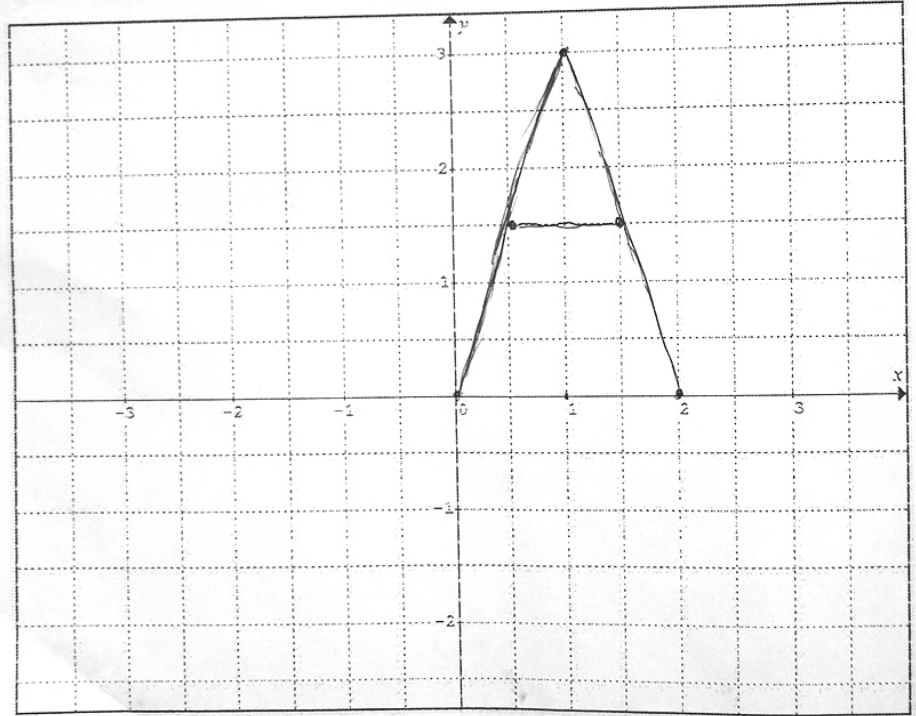

Figura 2 - Exemplo de enigmas resolvidos pelos alunos na "caça a coruja"

Os alunos ficaram animados com a proposta e tiveram a oportunidade de aprender matemática a partir de situações que os desafiaram. Os docentes, professores e licenciandos, constatam um aspecto relevante nessa dinâmica: embora a conclusão da atividade determinaria que um grupo teria resolvido os problemas-desafios antes de outros grupos, todos estiveram envolvidos de maneira solidária e cooperativa na realização do trabalho. A seguir destacamos imagens (figuras 3, 4 e 5) que refletem o envolvimento dos alunos na atividade.
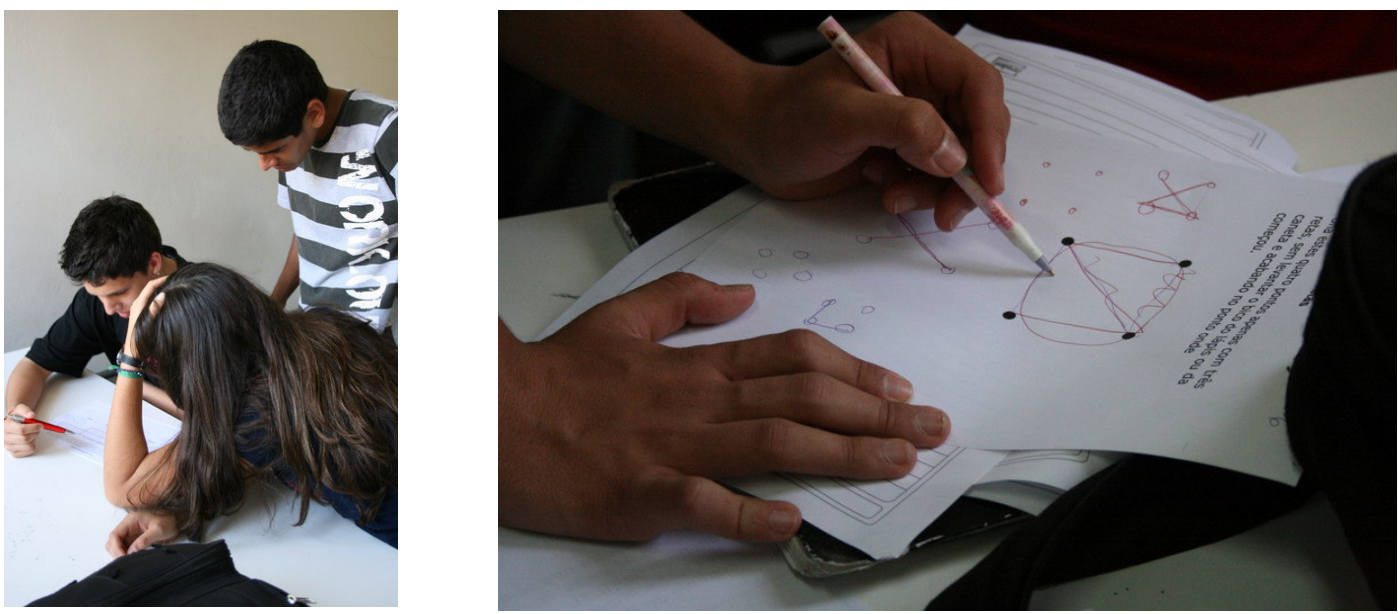

Figuras 3 e 4 - Imagem dos alunos no desafio "Caça a coruja" 


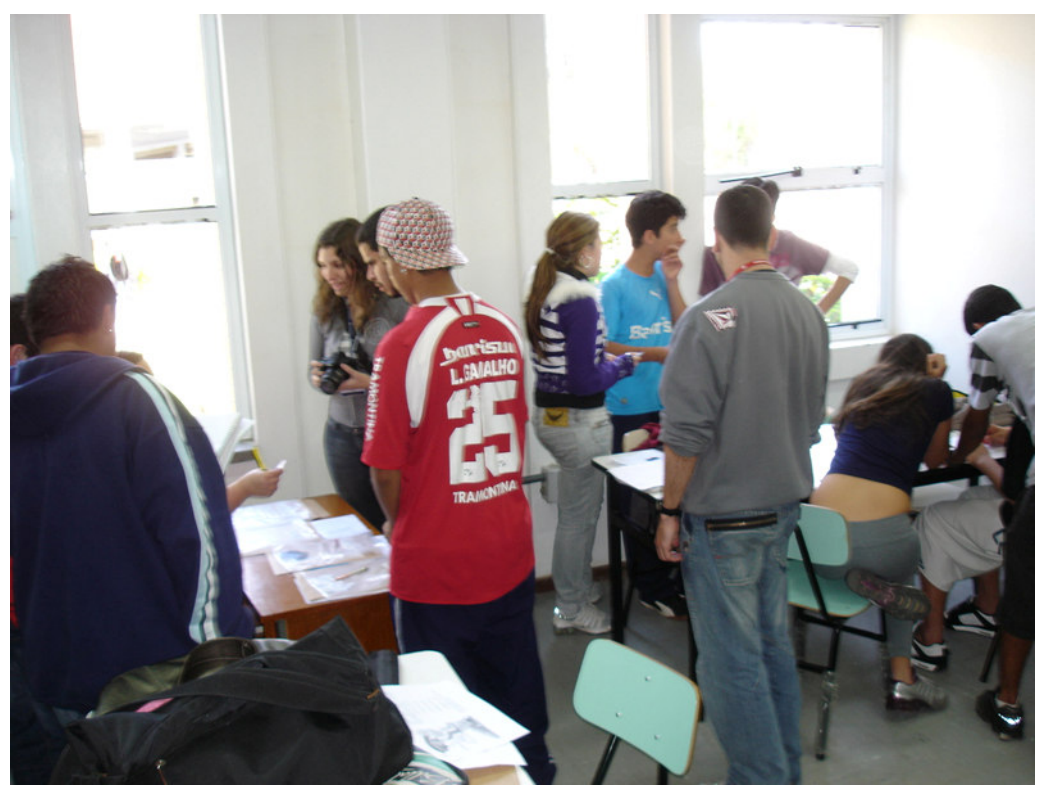

Figuras 5 - Imagem dos alunos no desafio "Caça a coruja"

A mudança de estratégia foi positiva e decidimos manter esta dinâmica nas aulas seguintes. A seguir descrevemos outras duas atividades realizadas no EC.

Detetive Matemático

Esta atividade é parecida com o conhecido jogo Detetive, mas fizemos algumas modificações que transformaram o jogo em um bem humorado "Detetive matemático".

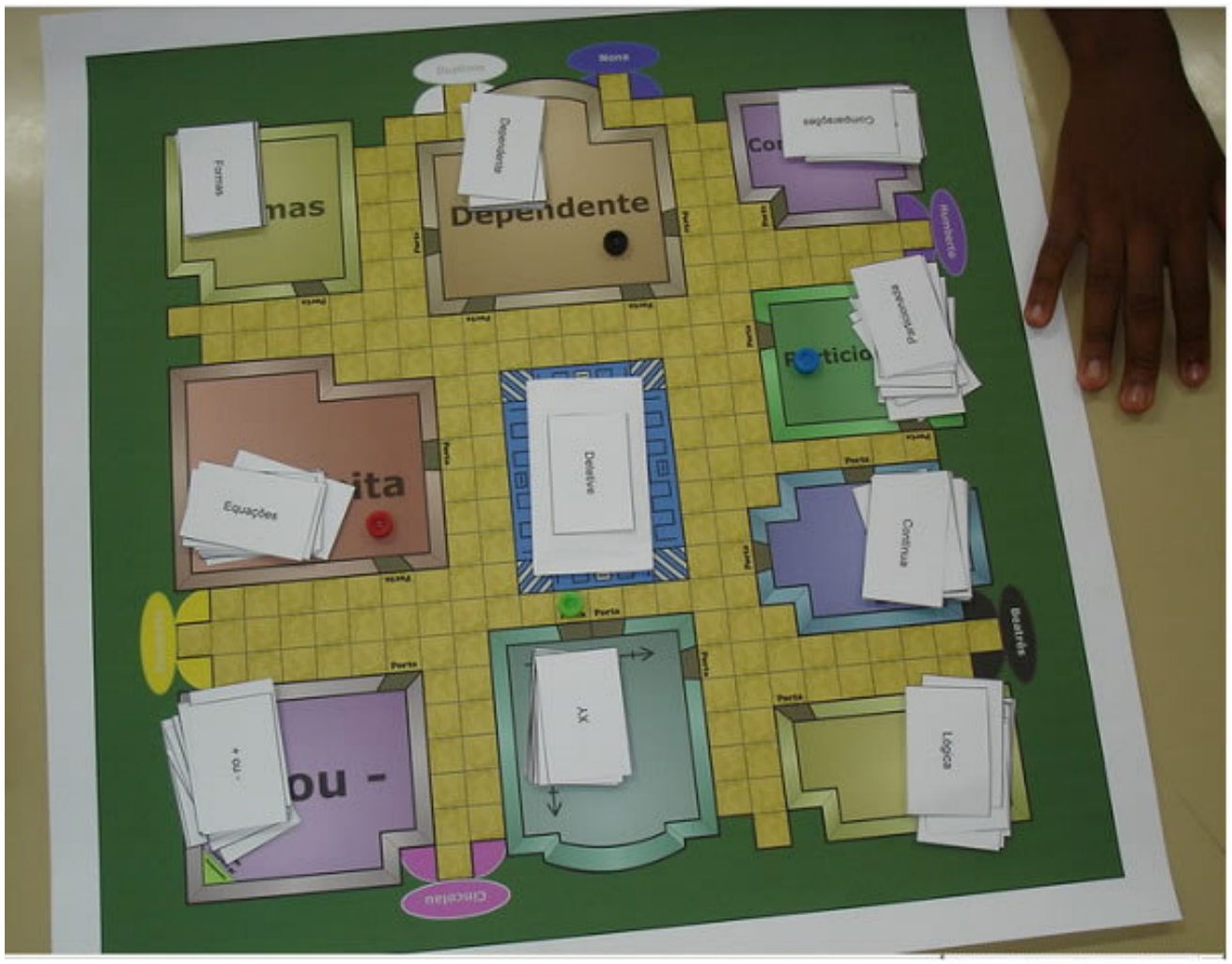

Figura 6 - Tabuleiro do Detetive Matemático 
Como podemos perceber na imagem acima, o tabuleiro do jogo é muito parecido com o jogo "Detetive". Realizando uma adaptação no jogo original, alteramos os nomes das salas. No lugar de "biblioteca", "sala de jogos", etc, as salas receberam denominações matemáticas: "sala + ou -“" (sala de operações com números inteiros), "sala das formas" (sala com problemas geométricos) e assim por diante. Os personagens também receberam nomes diferentes. No lugar de Sra Violeta, Sr. Black, etc, os personagens também eram "matemáticos": o Zeroberto o Humberto, o Cincolau, a Beatrês e outros. As armas do jogo ficaram: O compasso, a reta, etc. Em termos de regras, o desenvolvimento do jogo foi estruturado de forma similar ao original:

- existe uma carta para cada sala, arma e personagem;

- sorteia-se uma carta de cada tipo para formar uma trinca composta pelo assassino, arma e sala onde ocorreu o crime e coloca-se no envelope no centro do jogo sem que ninguém veja;

- as cartas restantes são distribuídas em número igual para cada jogador.

- p objetivo do jogo é solucionar o crime descobrindo a trinca presente no envelope.

- são 6 suspeitos, 6 armas e 9 locais, dando 324 possibilidades de crime.

- para decidir qual jogador começa jogando usamos os dados;

- cada jogador na sua vez lança os dados e move a peça que o representa no jogo de acordo com o número resultante da soma dos dados procurando entrar em uma sala;

- uma vez "dentro" de uma sala, o jogador deve dar um palpite, por exemplo: "Acho que foi o Cincolau, na Sala de Formas, com o Compasso."

- o próximo jogador, no sentido horário da mesa, deve mostrar apenas para o acusador, uma carta que desminta o palpite, por exemplo, a carta do Compasso.

- um palpite só pode ser dado pelo jogador no local em que ele está, assim, ele não pode estar na sala + ou - e dizer que o crime foi cometido na Sala Dependente, uma vez que precisa estar na sala para poder investigá-la. O jogador deve então, via palpites e as cartas que os outros jogadores vão mostrando para desmentir estes palpites, criar uma estratégia pra solucionar o crime.

Novamente constatamos uma conduta similar à ocorrida na atividade anterior: os estudantes trabalharam em clima de total cooperação. Apesar de serem adversários no jogo eles auxiliaram os colegas para resolver os enigmas propostos em cada sala.

Resolvendo problemas em conjunto

Como última atividade do semestre, propusemos para os alunos a seguinte dinâmica: formamos grupos de quatro alunos e distribuímos 1 problema para cada aluno. Ao término de 3 minutos os alunos trocavam de problema com os componentes do seu grupo e continuavam a resolver os problemas de onde o colega havia parado. A dinâmica continuava assim até que todos os alunos tivessem contribuído na solução de todos os problemas. Os problemas eram do tipo: "como você faria para calcular o volume de um grão de arroz?” ou então: "Como você faria para estimar o número de fios de cabelo na cabeça de uma pessoa?" Destacamos abaixo alguns extratos da resolução conjunta destes problemas pelos alunos. 


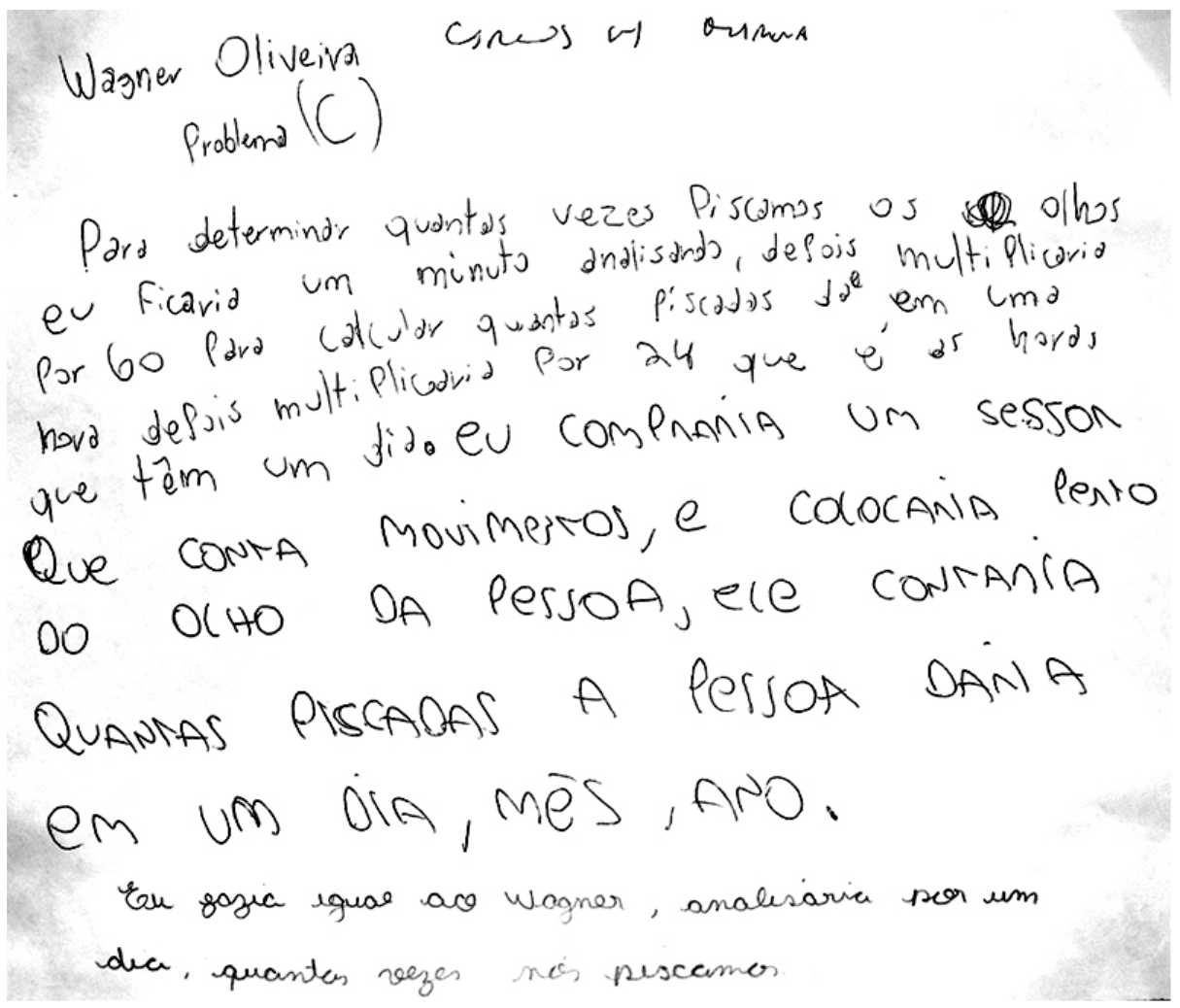

Figura 7 - problema "piscar olhos"

Em um segundo momento, pedimos que eles criassem os problemas para que os colegas resolvessem. Uma vez criados, tornamos a repetir a dinâmica de resolução. Abaixo destacamos alguns exemplos de problemas criados pelos alunos e das estratégias de resolução.

\section{Conclusões e Perspectivas}

Constatamos que aulas nas quais os alunos se sintam desafiados a buscarem por si mesmos a solução de problemas, construindo alternativas a partir da discussão com seu pares é uma maneira eficaz de proporcionar a eles um ambiente no qual desenvolvam sua autonomia, assumindo a responsabilidade por sua aprendizagem.

A análise dos resultados aponta para a comprovação de que o trabalho com vídeos do interesse dos alunos, ao invés de vídeos feitos com a finalidade primeira de apresentar conteúdos, serviu para motivar os alunos a participarem das aulas, deixando sua postura de espectadores e passando a atores e autores do processo de aprender. Além disso, as atividades propostas nas quais os alunos tinham de elaborar suas próprias idéias, explicar seu raciocínio, discutir e argumentar com os colegas tornou a Matemática mais 'real', próxima deles e não algo que aprendem na escola e cuja finalidade permanece obscura.

Dessa forma, pudemos observar que aulas nas quais os alunos se sintam desafiados a buscarem por si mesmos a solução de problemas, construindo alternativas a partir da discussão com seu pares é uma maneira eficaz de proporcionar a eles um ambiente no qual desenvolvam sua autonomia, assumindo a responsabilidade por sua aprendizagem.

Para além destas atividades, pretendemos, para o segundo semestre de 2009, reeditar as atividades desse Enriquecimento Curricular acrescentando novos episódios 
da série Numb3rs e de outras séries comerciais, desenvolvendo atividades integrando as áreas de Química, Física, Biologia e possíveis relações com Matemática.

\section{Referências}

JORBA, J. e LLADÓ, C. La actividad matemática y las habilidades cognitivoliguisticas In: Jorba, J. ,Goméz, I., Prat, A. Hablar y escribir para aprender Editorial Sintesis. Barecelona:1998

COLL, C., ONRUBIA, J. A construção de significados compartilhados em sala de aula: atividade conjunta e dispositivos semióticos no controle e acompanhamento mútuo entre professores e alunos IN: Coll,C. Edwards, D. Ensino, Aprendizagem e Discurso em Sala de Aula : aproximações ao estudo do discurso educacional. Artmed. Porto Alegre:1998 